\title{
Material characterisation of a painted beehive panel by advanced spectroscopic and chromatographic techniques in combination with hyperspectral imaging
}

\author{
Klara Retko ${ }^{1,2}$, Maša Kavčič ${ }^{1}$, Lea Legan ${ }^{1}$, Polonca Ropret ${ }^{1,2,3}$, Bojana Rogelj Škafar ${ }^{4}$, Yingwang Gao ${ }^{5}$, \\ John Gilchrist ${ }^{5}$, Matija Strlič2,6 and Irena Kralj Cigić ${ }^{2 *}$
}

\begin{abstract}
In this study, a painted beehive panel from the collection of the Slovene Ethnographic Museum was examined with respect to its material composition with the aim to reveal the painting technique. Due to the state of degradation due to outdoor weathering (UV irradiation, rainfall, extreme temperature and humidity fluctuations), as well as past conservation interventions, the object represented a complex analytical challenge. We aimed for non-invasive techniques (FTIR in reflection mode, Raman spectroscopy and hyperspectral imaging in the range of 400-2500 nm); however, in order to explore paint layers, cross-sections were also analysed using Raman spectroscopy. FTIR spectroscopy in transmission mode and gas chromatography coupled to mass spectrometry were also used on sample fragments. Various original materials were identified such as pigments and binders. The surface coating applied during conservation interventions was also characterised. Additionally, organic compounds were found (oxalate, carboxylate), representing transformation products. The potential use of Prussian blue as a background paint layer is discussed.
\end{abstract}

Keywords: Painted beehive panels, Cultural heritage, Reflection FTIR spectroscopy, Transmission FTIR spectroscopy, Non-invasive raman spectroscopy, GC-MS analysis, Hyperspectral imaging

\section{Introduction}

Painted beehive panels are an original folk art form unique to certain Slovenian-speaking regions. The colourfully painted flat wooden panels (ca. $13 \times 30 \mathrm{~cm}$ ) decorated the fronts of wooden beehives stacked under a roof, forming an open-air apiary or "bee-house". As such, the objects had to withstand outdoor weathering conditions including intensive UV irradiation, rainfall, extreme environmental fluctuations, as well as mechanical degradation, which resulted in extensive degradation of many beehive panels.

\footnotetext{
*Correspondence: irena.kralj-cigic@fkkt.uni-lj.si

2 Faculty of Chemistry and Chemical Technology, University of Ljubljana, Večna pot 113, 1000 Ljubljana, Slovenia

Full list of author information is available at the end of the article
}

Beekeeping is meaningful connection between people and the structured world of the bee society. They build special housing for bees, take care of them and collect the products of their activities. In a spiritual sense, beehives, as bee houses with painted panels, became a reflection of people's own views of themselves and the world in which they lived and struggled to survive. In the period of their most intensive production, i.e. from the mid-eighteenth century until the First World War, over 50,000 panels were painted. Most of them were painted by simple, self-taught painters who borrowed motifs from devotional cards, illustrated Bibles from Germany, prints, newspaper and book illustrations, but were often inspired also by the artist's own imagination. Most of the motifs are figurative, including over 600
Springer Open

(c) The Author(s) 2020. This article is licensed under a Creative Commons Attribution 4.0 International License, which permits use, sharing adaptation, distribution and reproduction in any medium or format, as long as you give appropriate credit to the original author(s) and the source, provide a link to the Creative Commons licence, and indicate if changes were made. The images or other third party material in this article are included in the article's Creative Commons licence, unless indicated otherwise in a credit line to the material. If material is not included in the article's Creative Commons licence and your intended use is not permitted by statutory regulation or exceeds the permitted use, you will need to obtain permission directly from the copyright holder. To view a copy of this licence, visit http://creativeco mmons.org/licenses/by/4.0/. The Creative Commons Public Domain Dedication waiver (http://creativecommons.org/publicdomain/ zero/1.0/) applies to the data made available in this article, unless otherwise stated in a credit line to the data. 
different ones, of which a good half are religious motifs, while others have moral and satirical content.

Painted beehive panels are testaments of popular creativity and significant collections exist in the Slovene Ethnographic Museum (Ljubljana, Slovenia, ca. 1000 objects) and The Museum of Apiculture (Radovljica, Slovenia, ca. 1500 objects), most of which can be digitally accessed $[1,2]$. Given the sizes of these collections, a general analytical strategy to explore the available material evidence would be advantageous to have in order to better manage the collections including their conservation.

Most existing research is art-historical or ethnographical and our current understanding of the painting process is based on twentieth century texts and observational studies [3-5]. A ground (likely containing chalk) or a preparatory paint layer of white colour might have been applied to the support [3, 4], although more recent research [5] and visual inspections suggest the wooden board was simply painted over with oil paint which also formed the background colour of the painted motif (this paint film is often brightly coloured, but can be white as well). Once the foundation layer dried up, the composition was stencilled or drawn with a pencil; this was then painted out such that forms were filled with mostly basic colour tones (modelled or not), and then painted further with details and contours. Each layer of paint was left to dry before the next one was applied. Oil paints, probably hand-made using locally available linseed oil as a paint binder and oil of turpentine as a paint thinner [5], might have been used in most cases, although tempera paints and binders such as poppy seed oil, mastic resin, egg white and egg-varnish tempera are mentioned as well [3, 4]. Among the colouring agents possibly used for paint preparation, durable mineral pigments of local production are generally mentioned [5], including earth pigments, golden ochre, Indian red, sooth black, vine black, cinnabar/vermilion, green earth, Schweinfurt (emerald) green and ultramarine [4]. Painted panels might have even been originally coated/varnished with bleached linseed oil mixed with mastic resin [4].

Spectroscopic and separation techniques such as Raman, FTIR and GC-MS are well established in the investigation of heritage materials $[6,7]$ including in the analysis of panel paintings $[8,9]$, and imaging spectroscopy was recently explored by Delaney et al. [10]. In a study of an Italian early renaissance panel painting, a combination of different molecular and elemental spectroscopic imaging methods was shown to provide insight into artistic materials, pigment distribution and underdrawings [11]. Further multimodal chemical imaging combining hyperspectral diffusive reflectance, luminescence and X-ray fluorescence was presented for analysis of the production technology of the painting, including mapping of wax and other organic materials [12].

For characterisation of drying oils gas chromatography coupled to mass spectrometry (GC-MS) is often used to determine the palmitic-stearic and azelaic-palmitic acid ratios, on the basis of which the most frequently used drying oils (linseed oil, poppyseed oil and walnut oil) can be reliably identified in the case of undegraded materials $[13,14]$. In the analysis of degraded binding media, accurate identification is not straightforward and the ratios depend also on the mixture of drying oils with pigments and other organic binders (e.g. waxes) [15].

In the present study, the material composition of the painted beehive panels was studied in order to explore the painting technique. Paint stratigraphy was researched to investigate the hypothesis that contours of painting compositions are generally better preserved due to greater number of paint layers which constitute such depicted segments and therefore better protect the wooden support $[4,5]$, and to explore the background paint layer which is mostly deteriorated.

\section{Materials and methods \\ Description of the painted beehive panel, preparation of the removed samples and analytical strategy}

The panel depicting the theme of "A fight over a pair of men's trousers" (ref. no. PK2, 1882) (Fig. 1) from the collection of the Slovene Ethnographic Museum has no catalogued information regarding its provenance and history, as is the case with many painted beehive panels [5]. The panel lacks many areas of the painted composition, as evident from Fig. 1a. The most preserved are the contours, along with some other parts of the composition; however, the panel almost entirely lacks any hint of the paint film depicting the background. It is executed on wood with dimensions ca. $13 \times 35 \times 1.5 \mathrm{~cm}$.

The photographs of the panel in visible light and under ultraviolet (UV) radiation are presented in Fig. 1. For UV fluorescence photography, UV-A fluorescent bulbs Osram L 36W/73 and a Canon EOS 350D camera with EF-S18-55 mm f/3.5-5.6 II lens and UV-cut-off filter were used.

The locations of the point-based non-invasive analyses are marked in Fig. 1a ("A" indicates FTIR spectroscopy in reflection mode, " $\mathrm{R}$ " indicates Raman spectroscopy). "Areas (PK2-1, PK2-2, PK2-2b, PK2-3, PK2-4), in which sampling was performed are denoted in Fig. 1a as well. The size of the removed samples was approximately 1 $\mathrm{mm}^{2}$. The samples were removed with a scalpel. A part of these samples containing strata from the support to the uppermost layer was used for FTIR spectroscopy (PK21, PK2-2, PK2-3), GC-MS analyses (PK2-1 and PK2-2), and for preparation of cross-sections used in optical and 

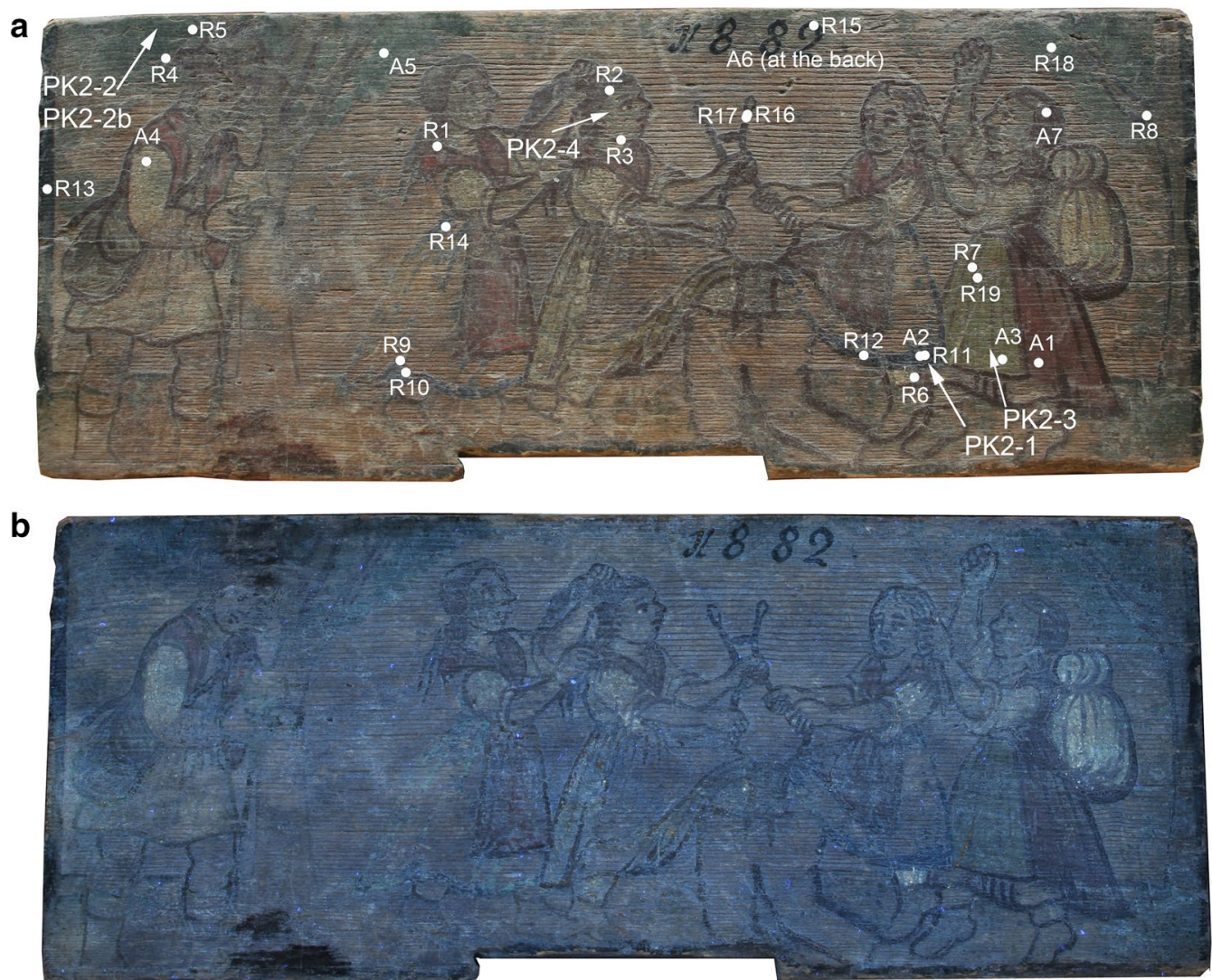

Fig. 1 Photographs of the painted beehive panel "A fight over a pair of men's trousers" (Slovene Ethnographic Museum, ref. no. PK2, 1882): a in visible light and $\mathbf{b}$ under UV radiation source. The sampling locations for FTIR spectroscopy in reflection mode (A), Raman spectroscopy (R), and areas of removed samples for cross-sections and transmission FTIR analysis (PK2-1, PK2-2, PK2-2b, PK2-3, PK2-4) are indicated

Raman microscopy. The exception was sample PK2-4 used in its raw form for Raman spectroscopy only. Sample PK2-2b (as a cross-section) was investigated using optical and Raman microscopy only.

To prepare the cross-sections, samples were embedded in the casting resin Kristal PS (transparent two-component copolymer resin, Samson Kamnik, d.o.o., Slovenia), and then polished using silicon carbide abrasive papers and paraffin oil. Finally, the samples were cleaned in petroleum ether in ultrasonic bath.

\section{Fourier Transform Infrared (FTIR) spectroscopy}

Fourier Transform Infrared (FTIR) transmission spectra were recorded using a Perkin Elmer Spectrum100 FTIR spectrophotometer coupled to a Spotlight FTIR microscope equipped with nitrogen cooled mercury-cadmium telluride (MCT) detector. The samples investigated by FTIR transmission mode were taken from the painted beehive panels, placed between the windows of a diamond anvil cell and examined under microscope.
Non-invasive FTIR analysis of the panel's surface was carried out with a portable Alpha-R spectrometer from Bruker Optics. The pseudo-absorption spectra $\left(\mathrm{A}^{\prime}=\log \right.$ $(1 / R), R=$ reflectance) were collected in reflection mode between 7500 and $400 \mathrm{~cm}^{-1}$, at $4 \mathrm{~cm}^{-1}$ spectral resolution. 160 scans per sample were averaged and for the background measurement, a gold mirror was used. An integrated video camera controlled and monitored the sampling area. Processing of the FTIR data was implemented using Bruker OPUS software.

\section{Raman spectroscopy}

The spectra were recorded using a $785 \mathrm{~nm}$ and $514 \mathrm{~nm}$ laser excitation lines with a Horiba Jobin Yvon LabRAMHR800 Raman spectrometer coupled to an Olympus BXFM optical microscope. The spectra were recorded using $\times 50$ LWD objective lens and/or $\times 100$ objective lens and a 600 grooves $/ \mathrm{mm}$ grating. A multichannel, air-cooled CCD detector was used. Experimental parameters (time of exposure, accumulation, power at the sample, etc.) were adjusted according to the specifics 
of the samples. The specific parameters used for the collection of the presented spectra are included in the figures' captions.

The dimensions of the panel allowed investigation directly under the microscope in a non-invasive manner. The panel was placed directly under the objective and the spectra were then collected using the $\times 50$ LWD objective from the locations of the interest. Further analysis was done also on the cross-sections of the samples. In such case, the cross-section was placed under the microscope and investigated using $\times 100$ objective lens. Spectral interpretation and identification of the materials were done in comparison with own spectral database and the literature $[16,17]$ and the data are included in Additional file 1.

\section{Hyperspectral imaging}

The system comprises of a high-resolution ClydeHSI Hyperion Art Scanner, which was used with either a push-broom visible and near-infrared (VNIR; 400$1000 \mathrm{~nm}, \Delta \lambda=3 \mathrm{~nm}$ (FWHM)) or short-wavelength infrared (SWIR; 900-2500 nm, $\Delta \lambda=10 \mathrm{~nm}$ (FWHM)) hyperspectral cameras each capable to provide a spatial resolution on the panel of 37 and $24 \mu \mathrm{m}$ respectively. Spectral image cubes in the object dimensions $(13 \times 35 \mathrm{~cm})$ were collected. The scanner was fitted with a dual distance sensor to ensure that even curved surfaces will remain in focus. Illumination was made using a tungsten light source that has a smooth spectral emission from approximately $350 \mathrm{~nm}$ to $3500 \mathrm{~nm}$. The illumination level in the visible spectrum was ca. 2000 lx. At the start and end of each scan a reflective white tile was measured to record the instrument spectral-spatial response function, and this was used to convert the raw data signal into reflectance and absorption data. Subsequently, data analysis was made using Principal Components Analysis (PCA) and Spectral Angle Mapping (SAM) methods to achieve distributions of the material across the panel.

\section{Optical microscopy}

The cross-sections of the samples were examined using an Olympus BX 60 microscope connected to an Olympus SC-50 video camera using visible and ultraviolet (UV) illumination, the latter emitted from a $\mathrm{Hg}$ bulb Ushio USH-1030L.

\section{GC-MS Analysis}

A sample $(0.5-2 \mathrm{mg})$ was treated in glass vials with $3 \mathrm{~mL}$ of $0.5 \mathrm{M}$ methanolic solution of $\mathrm{NaOH}$ and $300 \mu \mathrm{L}$ of dichloromethane, flushed with nitrogen, closed and heated for $10 \mathrm{~min}$ at $90^{\circ} \mathrm{C}$. The vials were cooled briefly before addition of $3 \mathrm{~mL}$ of a $12 \%$ methanolic solution of $\mathrm{H}_{2} \mathrm{SO}_{4}$, again flushed with nitrogen, closed and heated for $10 \mathrm{~min}$ at $90{ }^{\circ} \mathrm{C}$. The vials were then cooled to room temperature. $3 \mathrm{~mL}$ deionized water and $1.5 \mathrm{~mL}$ hexane were added to the vials and then fatty acids methyl esters (FAMEs) were extracted by vigorous shaking for about 1 min. Following centrifugation, the hexane layer was transferred into a vial for GC-MS analysis.

GC-MS analyses were carried out using Thermo Scientific Focus GC with a mass spectrometric detector Thermo Scientific ISQ controlled by the software Thermo Xcalibur version 3.0. Chromatographic separation was achieved using a Supelco, Omegawax 320 capillary column (bonded polyethylene glycol stationary phase; $30 \mathrm{~m} \times 320 \mu \mathrm{m} \times 0.25 \mu \mathrm{m})$. The injector temperature was set at $200{ }^{\circ} \mathrm{C}$ and the interface temperature at $250{ }^{\circ} \mathrm{C}$. The oven was programmed from $185^{\circ} \mathrm{C}$, then increased at $1{ }^{\circ} \mathrm{C} /$ min to $215{ }^{\circ} \mathrm{C}$, stayed constant for 9 min and then decreased at $10{ }^{\circ} \mathrm{C} / \mathrm{min}$ to $185{ }^{\circ} \mathrm{C}$. The injection volume was $2 \mu \mathrm{L}$ and the inlet was operated in split mode, with a 1:5 split ratio. The carrier gas was helium at a constant flow of $2 \mathrm{~mL} / \mathrm{min}$. Identification was based on NIST mass spectral library (NIST 08) and NIST mass spectral search programme (Version 2.0).

\section{Results and discussion}

The painted beehive panel was examined to obtain a comprehensive picture of the applied materials and their potential transformations (Table 1).

\section{Inorganic materials (pigments, fillers, extenders, adulterants) \\ General investigation of paint layers}

Using Raman and/or FTIR spectroscopy, we detected several different particulate materials (Table 1), such as cinnabar/vermilion, iron oxide (likely of the haematite type), lead oxide/minium, iron hydroxide (likely of the goethite type), carbon-based black, Prussian blue, ultramarine, lead white, calcium carbonate, anatase, and barium sulphate. Majority of these identified materials are most likely prime pigments, whereas some of the latter listed might be present in the paints as natural pigment components, impurities, or additives (e.g. fillers, extenders, adulterants). The presence of Emerald green and chrome yellow was suggested but could not be completely confirmed.

The best preserved areas of PK2 are the contours of the painted figures and objects, mostly executed in a darker red-brown colour, along with the draperies painted in red, and some of the partially remaining whitish, green, brown, blue and black painted sections. In the green coloured regions such as tree foliage (R4, R5, R18, A5, Fig. 1a) and the lighter green apron of the female figure (R7, R19, A3), barium sulfate was detected using Raman spectroscopy, along with Prussian blue (R5, R18). Both 
Table 1 The materials as identified on the painted beehive panel (PK2) at the different sampling locations as marked in Fig. 1a, along with the methods used

\begin{tabular}{|c|c|c|c|c|c|c|}
\hline Material & Chemical formula & Raman & FTIR-reflection & Raman microscopy & FTIR-transmission & GC-MS \\
\hline $\begin{array}{l}\text { Lead white (hydrocer- } \\
\text { ussite) }\end{array}$ & $2 \mathrm{PbCO}_{3} \cdot \mathrm{Pb}(\mathrm{OH})_{2}$ & & & $\begin{array}{l}\text { PK2-1, PK2-2b, PK2-3, } \\
\text { PK2-4 }\end{array}$ & & \\
\hline Anatase & $\mathrm{TiO}_{2}$ & & & PK2-2b & & \\
\hline barium sulfate & $\mathrm{BaSO}_{4}$ & R4, R5, R7 R18, R19 & $\mathrm{A} 1, \mathrm{~A} 3, \mathrm{~A} 4, \mathrm{~A} 5, \mathrm{~A} 7$ & $\begin{array}{l}\text { PK2-1, PK2-2, PK2-2b, } \\
\text { PK2-3, PK2-4 }\end{array}$ & PK2-1, PK2-2, PK2-3 & \\
\hline Calcium carbonate & $\mathrm{CaCO}_{3}$ & R6 & & PK2-1 & & \\
\hline $\begin{array}{l}\text { Iron oxide (likely } \\
\text { haematite type) }\end{array}$ & $\mathrm{Fe}_{2} \mathrm{O}_{3}$ & $\mathrm{R} 2, \mathrm{R} 3, \mathrm{R} 16, \mathrm{R} 17$ & & PK2-1, PK2-2b & & \\
\hline $\begin{array}{l}\text { Iron hydroxide (likely } \\
\text { goethite type) }\end{array}$ & $\mathrm{FeOOH}$ & & & PK2-2b & & \\
\hline Cinnabar/vermilion & $\mathrm{HgS}$ & $\mathrm{R} 1, \mathrm{R} 3, \mathrm{R} 8$ & & PK2-1, PK2-4 & & \\
\hline Lead oxide (minium) & $\mathrm{Pb}_{3} \mathrm{O}_{4}$ & & & PK2-4 & & \\
\hline Ultramarine & $\mathrm{Na}_{8}\left[\mathrm{Al}_{6} \mathrm{Si}_{6} \mathrm{O}_{24}\right] \mathrm{S}_{\mathrm{n}}$ & $\mathrm{R} 9, \mathrm{R} 10, \mathrm{R} 11, \mathrm{R} 12, \mathrm{R} 14$ & & PK2-1 & PK2-1 & \\
\hline Prussian blue & $\mathrm{Fe}_{4}\left[\mathrm{Fe}(\mathrm{CN})_{6}\right]_{3} \cdot \times \mathrm{H}_{2} \mathrm{O}$ & $\mathrm{R} 5, \mathrm{R} 18$ & $\mathrm{~A} 1, \mathrm{~A} 2, \mathrm{~A} 3, \mathrm{~A} 4, \mathrm{~A} 5, \mathrm{~A} 7$ & $\begin{array}{l}\text { PK2-1, PK2-2, PK2-2b, } \\
\text { PK2-3, PK2-4 }\end{array}$ & PK2-1, PK2-2, PK2-3 & \\
\hline Carbon-based black & C & $\mathrm{R} 3, \mathrm{R} 13, \mathrm{R} 15, \mathrm{R} 16, \mathrm{R} 17$ & & & & \\
\hline Glycerolipids & & & $\begin{array}{c}\mathrm{A} 1, \mathrm{~A} 2, \mathrm{~A} 3, \mathrm{~A} 4, \mathrm{~A} 5, \mathrm{~A} 6 \\
\text { (at the back), A7 }\end{array}$ & & PK2-1, PK2-2, PK2-3 & PK2-1, PK2-2 \\
\hline Plant terpenoid resin & & & $\mathrm{A} 1, \mathrm{~A} 2, \mathrm{~A} 3, \mathrm{~A} 4, \mathrm{~A} 5, \mathrm{~A} 7$ & & PK2-1, PK2-3 & \\
\hline Beeswax & & & $\begin{array}{l}\mathrm{A} 1, \mathrm{~A} 2, \mathrm{~A} 5, \mathrm{~A} 6, \mathrm{A7}, \\
\mathrm{A} 3, \mathrm{~A} 4^{\#}\end{array}$ & & PK2-2, PK2-3 & PK2-1, PK2-2 \\
\hline Oxalate & & & $\mathrm{A} 1, \mathrm{~A} 2, \mathrm{~A} 3, \mathrm{~A} 4$ & & PK2-1, PK2-2, PK2-3 & \\
\hline Carboxylate & & & & & PK2-1, PK2-3 & \\
\hline Carnauba wax & & & & & PK2-2 & \\
\hline
\end{tabular}

\# Present in traces

were confirmed with the FTIR spectra as well. Raman analyses corroborated the detection of cinnabar/vermilion in the red draperies (R1, Fig. 1a), although in one red area (A1, Fig. 1a) FTIR showed the presence of Prussian blue as well. Whether the latter is a component of the same or of an underlying stratum could not be determined.

The reddish-brown contours show the presence of iron oxide and/or carbon-based black (R2, R3, R16, R17, Fig. 1a) with possible presence of cinnabar/vermilion as well (R3, R8, Fig. 1a). All the remaining blue segments on the panel were identified as ultramarine with Raman spectroscopy (R9-R12, R14, Fig. 1a); however, using FTIR in reflective mode, Prussian blue was also detected (A2, Fig. 1a) which could either be a part of the same or of an underlying layer.

There are several whitish areas still preserved on the panel; however, it wasn't possible to identify the pigment using Raman analysis, with the exception of a possible presence of calcium carbonate in one location (R6, Fig. 1a). Furthermore, FTIR again showed the presence of Prussian blue in one of the white areas (A4, Fig. 1a). Calcium carbonate was detected also on PK2-1 in the layer containing ultramarine, although this could be considered as an impurity. Using Raman spectroscopy, lead white was detected as a white pigment by means of invasive analysis only in the cross-sections of PK2-1, PK2-2b and PK2-3, in the paint layer closest to the wooden support. Barium sulfate was found in the majority of areas of both darker and lighter green colour, and in particular in all point analyses where Prussian blue was identified as well (R5, R18, A1, A3-A5, A7, Fig. 1a) and might be present as an adulterant or extender of the main pigment(s) used in these paints.

Anatase was identified only in the cross-section of the sample PK2-2b with a single green paint layer on the wooden support, but could be considered as an impurity. In the same cross-section an ochre-coloured particle, identified as iron oxide hydroxide, likely of goethite type, was detected only in one point. Lead oxide (minium) was detected on the surface of the sample PK2-4 and could have been used in the pigment mixture (along with the identified lead white and cinnabar/vermillion) for skin tones of the figures. The detection of Emerald green and chrome yellow could not be confirmed; the former was indicated in the bottom paint layer of PK2-1 and the latter in the lower part of the seemingly single paint layer in PK2-2. Additional 
information is needed to verify the presence of these two pigments.

\section{Investigation of green paints}

It was not possible to obtain the exact pigment composition of the green paints using either FTIR spectroscopy in reflection mode or non-invasive Raman spectroscopy. In the locations R4, R5, A5 (Fig. 1a) barium sulfate (with Raman modes at 456, 464 and $989 \mathrm{~cm}^{-1}$; spectrum not shown) and/or Prussian blue (with Raman bands at 281, 539 and $2155 \mathrm{~cm}^{-1}$; spectrum not shown) were detected. These locations were additionally examined with hyperspectral imaging (Fig. 2), and areas with similar spectral features were mapped (highlighted in purple). R4, R5 and A5 are therefore likely to have similar mixtures of pigments.

Based on the identification of Prussian blue using spectroscopic analyses in R5 and A5 (Fig. 1a), the green areas could be composed of a mixture of blue (Prussian blue) and yellow pigments. To gain better insight, samples PK2-2 and PK2-2b were removed to examine the cross-sections (Fig. 3a, b). Optical microscopy of PK2-2 (Fig. 3a) showed what appear like large pigment particles (some measuring $\sim 10 \mu \mathrm{m}$ and more) that seem to be of emerald rather than of blue colour, with almost no visual indication of a possible presence of yellow pigments (particles of blue and yellowish to reddish colour are noticeable within the sample, however, they are barely visible).

Since the prevailing colour of pigment particles seems to be greenish, the current suggested hypothesis is that the particles might belong to a chrome green pigment or one of the possible forms of Prussian green [18]. A more detailed investigation was not possible. Similar hypothesis was established after optical microscopy of PK2$2 \mathrm{~b}$ (Fig. 3b). The presence of yellow pigments could not be detected using the analytical techniques employed within this study as well. One exception is the possible presence of chrome yellow (lead chromate) detected by Raman spectroscopy using excitation at $514 \mathrm{~nm}$ in the cross section of PK2-2 (Fig. 3a). Although the Raman signal (Fig. 3c) was obscured by fluorescence, a weak band at $\sim 840 \mathrm{~cm}^{-1}$ could be attributed to chromate symmetric stretching mode $[19,20]$. Although the $785-\mathrm{nm}$ line offers more spectral information on the structure of lead
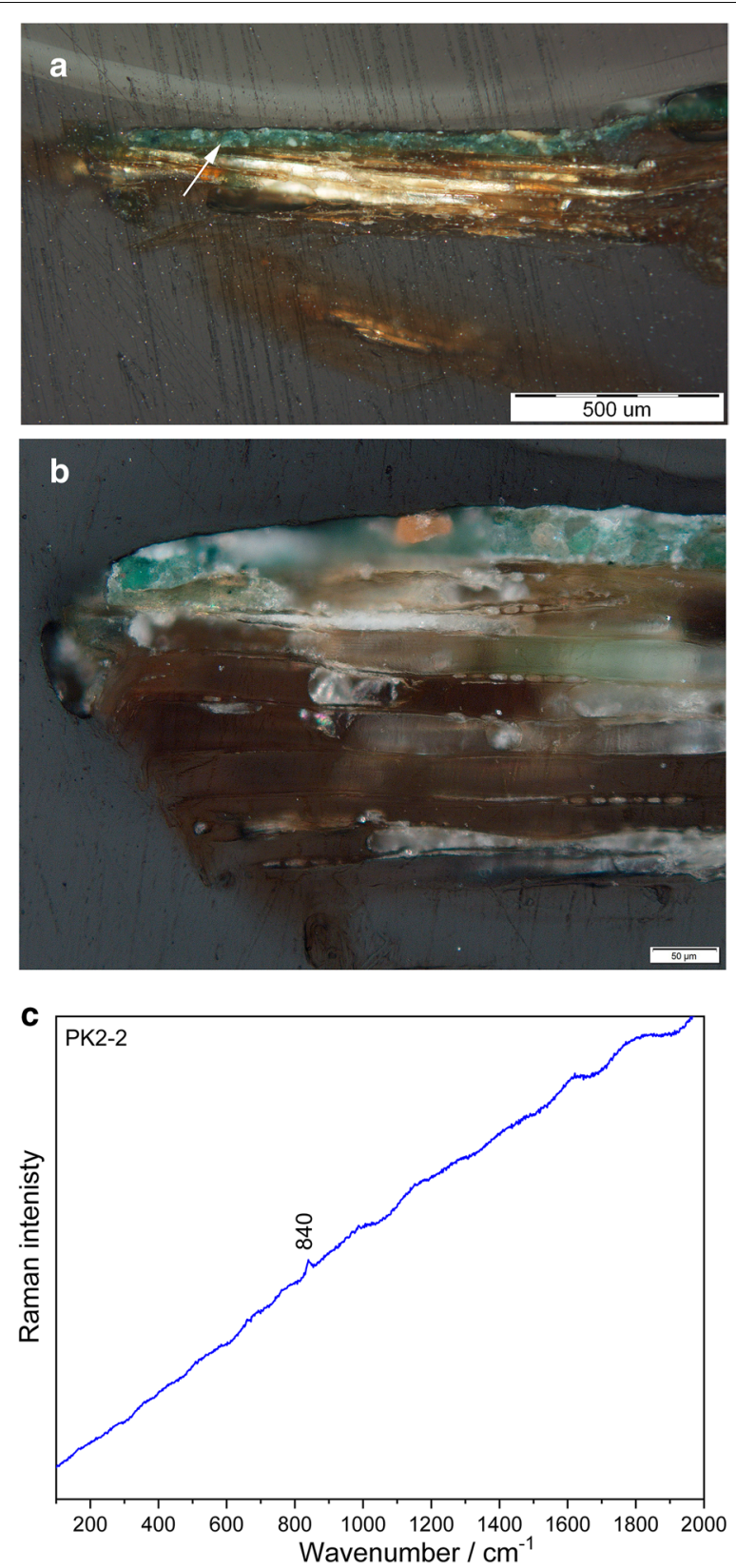

Fig. 3 Optical micrographs of the cross-sections of a PK2-2 (visible light/ $\times 10$ magnification) with the location of Raman analysis indicated, b PK2-2b (visible light/× 20 magnification), and c a Raman spectrum obtained on the location marked in $\mathbf{a}$, implying the presence of lead chromate $\left(\lambda_{0}=514 \mathrm{~nm}\right)$

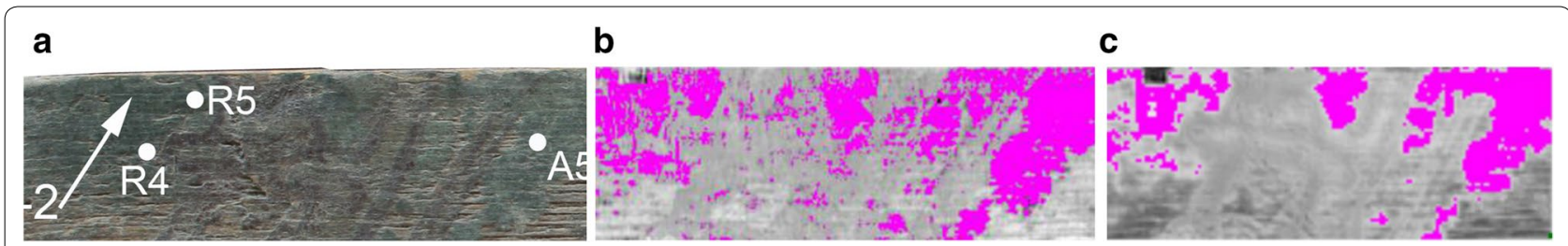

Fig. 2 Detail of the panel with R4, R5 and A5 sampling locations: a RGB image, b false-colour VNIR PC1, c false-colour SWIR PC1 
chromate-based compounds [20] and it could lead to reduction of fluorescence, no satisfactory results enabling unambiguous confirmation of chromate were obtained. Since the majority of particles appear greenish, and the analysis confirmed the presence of Prussian blue overall, as well as barites with the possible presence of chrome yellow, a plausible interpretation could be the use of chrome green. The other possible green pigments, such as pigments/mixtures under the term "Prussian green", need further investigation. The same can be concluded for PK2-3 ("Investigation of the support" section) of a lighter green colour, composed of a lower greenish and an upper yellowish layer, where the results of Raman and transmission FTIR spectroscopy indicate the presence of Prussian blue, barium sulfate and possibly lead white.

\section{Blue paints and a possible background paint}

It appears, upon visual inspection, that the best preserved areas might be those that were originally composed of more than one paint layer. It is impossible to identify the colour of the painted background since it is almost completely absent (and likely applied as a single-layer application across the entire panel surface). However, on closer visual inspection, a bluish or perhaps a greenish layer appears to have been applied, as visible also on the faces of the female figures, where the uppermost flesh colour tones are present only as minute residues.

Non-invasive investigations using reflection FTIR and Raman spectroscopy (locations R11, A2, Fig. 1a) of a dark blue contour of a dress led to different results. Namely, Raman spectroscopy (Fig. 4a) showed the presence of ultramarine on R11 (characteristic band at $547 \mathrm{~cm}^{-1}$ ), and FTIR spectroscopy indicated Prussian blue on A2.
The presence of Prussian blue was confirmed by the reflection infrared spectrum (Fig. 4b), based on the characteristic $\mathrm{C}=\mathrm{N}$ stretching vibration at $2085 \mathrm{~cm}^{-1}$ and derivative-like spectral features of the $\mathrm{Fe}-\mathrm{O}$ group located at $630-430 \mathrm{~cm}^{-1}$ [21]. In addition, the presence of Prussian blue was confirmed by reflection FTIR spectroscopy in all the investigated locations (A1, A2, A3, A4, A5, A7). These areas are of different colours (red, blue, white, brown, light and dark green), it seems less likely for Prussian blue to be consistently present as part of the pigment mixtures. A possible interpretation would be the presence of Prussian Blue in the lower layers, e.g. as a potential background paint layer.

To investigate the matter further, the sample PK2-1 was taken from the dark blue contour of a garment (Fig. 1a). This consisted of all stratigraphic layers-from the wooden support to paint layers as evident in the optical micrograph of the cross-section (Fig. 5a). Two paint layers are present: a lower one of lighter blue/ greenish-blue colour and an upper one of darker blue colour. The Raman spectrum (Fig. 5b) at the spot R1 in Fig. 5a revealed the characteristic ultramarine band at $547 \mathrm{~cm}^{-1}$, while the spectrum at R2 confirmed the presence of Prussian blue based on the characteristic bands at $276,537,2092,2155 \mathrm{~cm}^{-1}$. At R2, barium sulfate (band at $990 \mathrm{~cm}^{-1}$ ) and lead white (band at $1049 \mathrm{~cm}^{-1}$ ) were detected as well. The sample PK2-1 was investigated also by infrared spectroscopy in transmission mode (Fig. 5c), where the band at $2087 \mathrm{~cm}^{-1}$ indicated the presence of Prussian blue [22]. A strong and broad band with maximum at $1079 \mathrm{~cm}^{-1}$ most probably belong to $\mathrm{Si}-\mathrm{Al}-\mathrm{O}$ asymmetric stretching vibration of ultramarine [22]. In addition, glycerolipids $\left(2927,2854,1739 \mathrm{~cm}^{-1}\right)$, oxalate
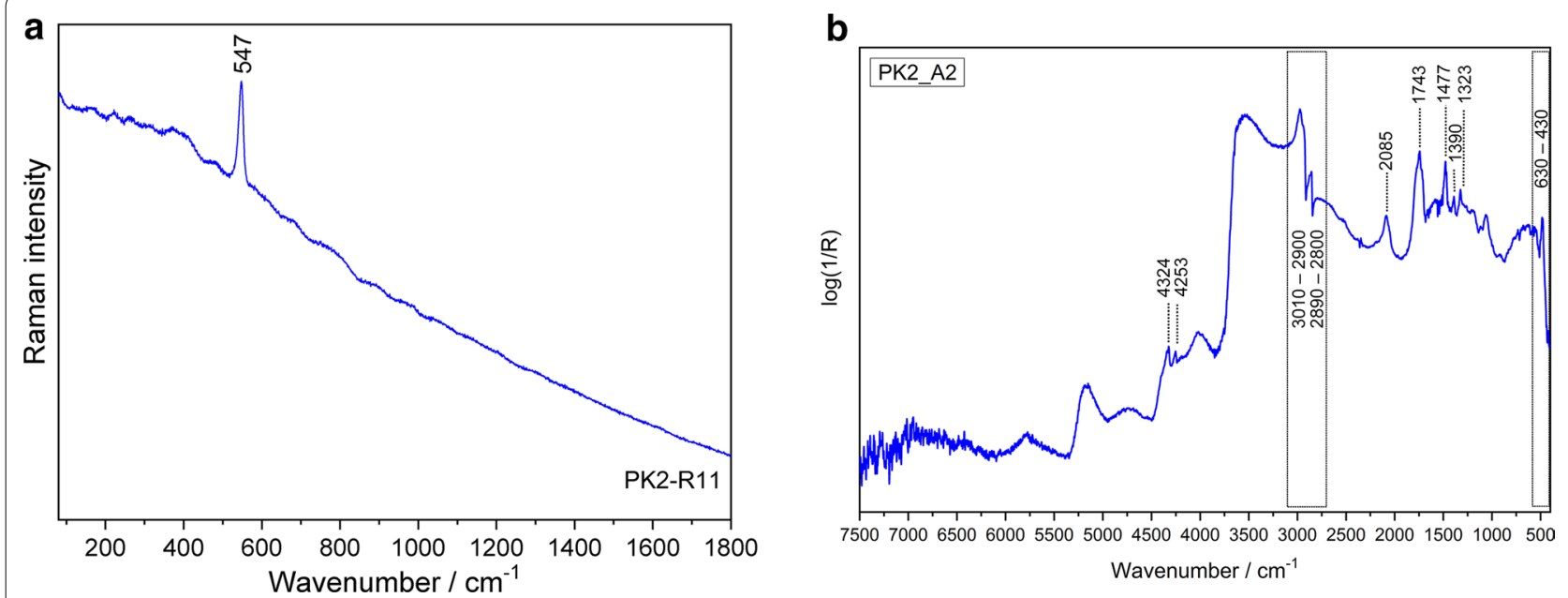

Fig. 4 a Raman spectrum at location R11, Fig. 1a, identifying ultramarine based on its characteristic band placed at $547 \mathrm{~cm}^{-1}\left(\lambda_{0}=785 \mathrm{~nm}\right) . \mathbf{b} A$ reflection FTIR spectrum obtained at A2 (Fig. 1a), identifying vibrations characteristic for Prussian blue, glycerolipids and plant terpenoid resin 

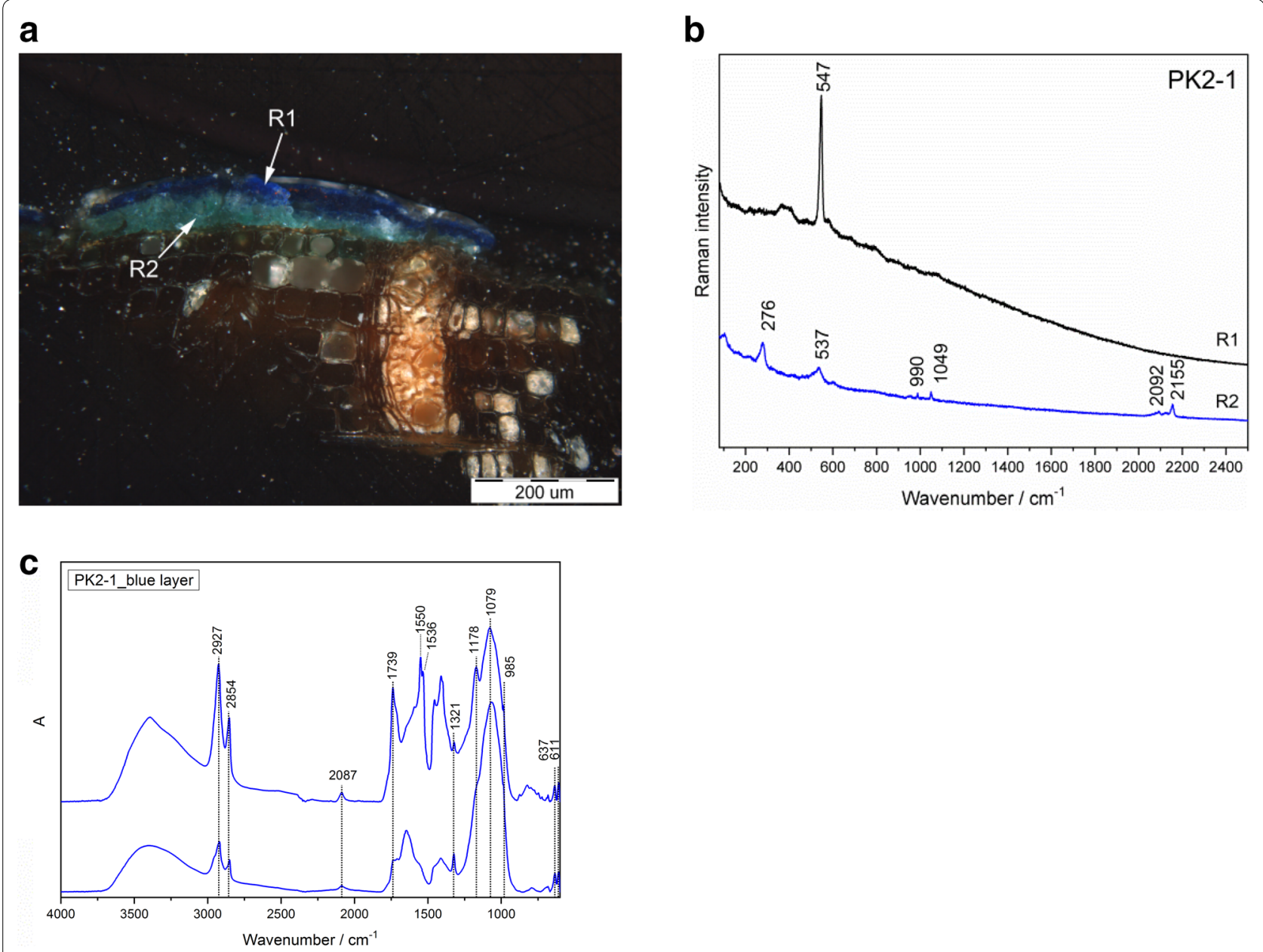

Fig. 5 a Optical micrograph of the sample PK2-1 taken from the painted beehive panel PK2 (for the sampling location see Fig. 1a) with measurement points of Raman analyses. b Raman spectra obtained on the sample PK2-1, identifying ultramarine at R1 and Prussian blue at R2. ( $\lambda_{0}=785 \mathrm{~nm}, 10 \mathrm{~s}$ exposition, 2 accumulations, $\sim 2 \mathrm{~mW}$ power). c FTIR spectrum (transmission mode) of blue layer present on sample PK2-1, identifying glycerolipid binder, barium sulfate, Prussian blue, ultramarine, oxalate and carboxylate

$\left(1321 \mathrm{~cm}^{-1}\right)$, carboxylate $(1550,1536 \mathrm{~cm}-1)$ and barium sulfate $\left(1178,985,637,611 \mathrm{~cm}^{-1}\right)$ were also detected. Typical, well-resolved bands of the latter compound placed at 1120 and $1084 \mathrm{~cm}^{-1}$, are hindered by the aforementioned broad band of ultramarine.

\section{Organic materials (binders, coating)}

Investigation of the front side (A2, Fig. 1a) using reflection FTIR revealed the presence of characteristic spectral features of glycerolipids at 4324, 4253, 3010-2900, 2890-2800 and $1743 \mathrm{~cm}^{-1}$ (Fig. 4b). Additional analysis of glycerolipid components was possible using GC-MS, where individual fatty acids and other components can be observed. There are characteristic palmitic/stearic $(\mathrm{P} / \mathrm{S})$ and azelaic/palmitic $(\mathrm{A} / \mathrm{P})$ ratios for linseed oil (typically 1.2 for $\mathrm{P} / \mathrm{S}$ and 1.3 for $\mathrm{A} / \mathrm{P}$ ) [14], which can be used for differentiation of drying oils. It is known that the observed ratios also depend on the mixture of the drying oil with pigments and other organic binders and on the age of the paint layers [15]. The ration can be as high as 1.5, therefore, identification of drying oils may be difficult. In the examined samples, only saturated and dicarboxylic fatty acids were observed (Fig. 6a), which indicates a degraded drying oil. Additional peaks marked with asterisks, which have the same retention time and mass spectra as the peaks observed in fresh beeswax (Fig. 6b) and representing long-chain compounds characteristic for waxes were also observed. This indicates a mixture of drying oil with beeswax, which was also indicated with FTIR, based on characteristic bands at 2956, 2918, 2850, 1737, 1707, 1473, 1467, 1170, 730 and $720 \mathrm{~cm}^{-1}$ (Fig. 6d) [23]. The P/S ratio determined for the investigated samples PK2-1 and PK2-2 were 1.5 and 


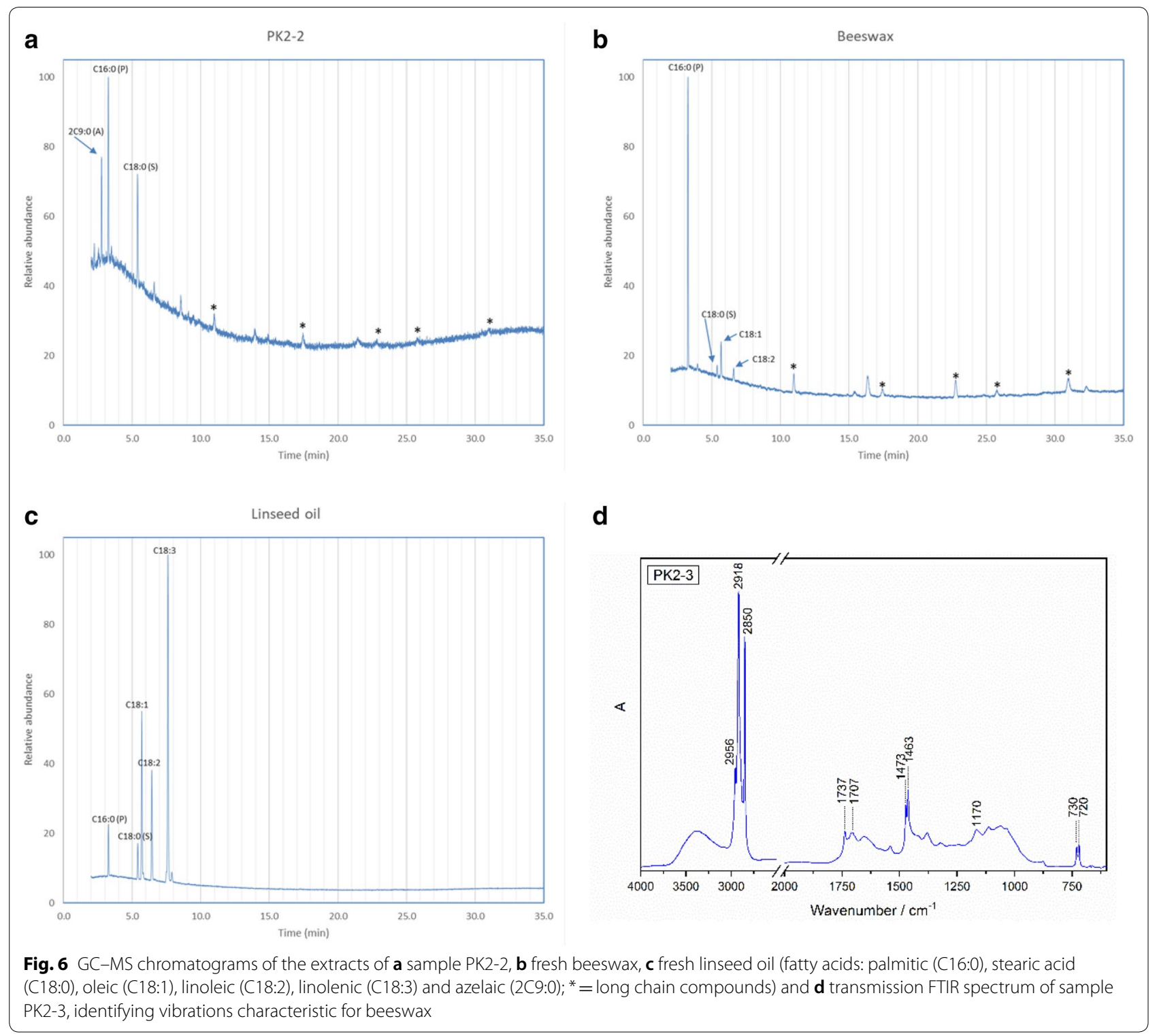

1.3 respectively and could be attributed to linseed oil, in agreement with the literature $[14,15]$. The $\mathrm{A} / \mathrm{P}$ ratios for samples PK2-1 and PK2-2 were 0.8 and 0.6 respectively and are not characteristic for linseed oil, however, they can be attributed to either a mixture with wax or else degradation causing large changes in this ratio, as was observed in the presence of pigments [15].

A plant terpenoid resin was confirmed on all investigated locations (A1-A5, Fig. 1a) on the front side of PK2 beehive panel, as indicated by the distinctive bands at $1477\left(\delta_{\mathrm{S}} \mathrm{CH}_{3}\right)$ and $1390\left(\delta_{\mathrm{AS}} \mathrm{CH}_{2}\right) \mathrm{cm}^{-1}$ (Fig. 4b) [24]. Within the samples PK2-1 and PK2-3, the resin was identified solely in the uppermost stratum, indicating that the resin component is probably part of a coating.

Hyperspectral imaging offered further information on the distribution of the plant terpenoid resin (Fig. 7a) and the beeswax (Fig. 7b). It can be observed that intensity of the spectral features for plant terpenoid resin is higher

Fig. 7 False-colour image for a plant terpenoid resin at $1702 \mathrm{~nm}$, b beeswax at $2309 \mathrm{~nm}$ and $\mathbf{c}$ hyperspectral data showing the ratio of intensities at $1702 \mathrm{~nm}$ (characteristic of resin) over $2309 \mathrm{~nm}$ (characteristic of beeswax). Higher numbers (red colours) represent higher reflectance intensity 
a
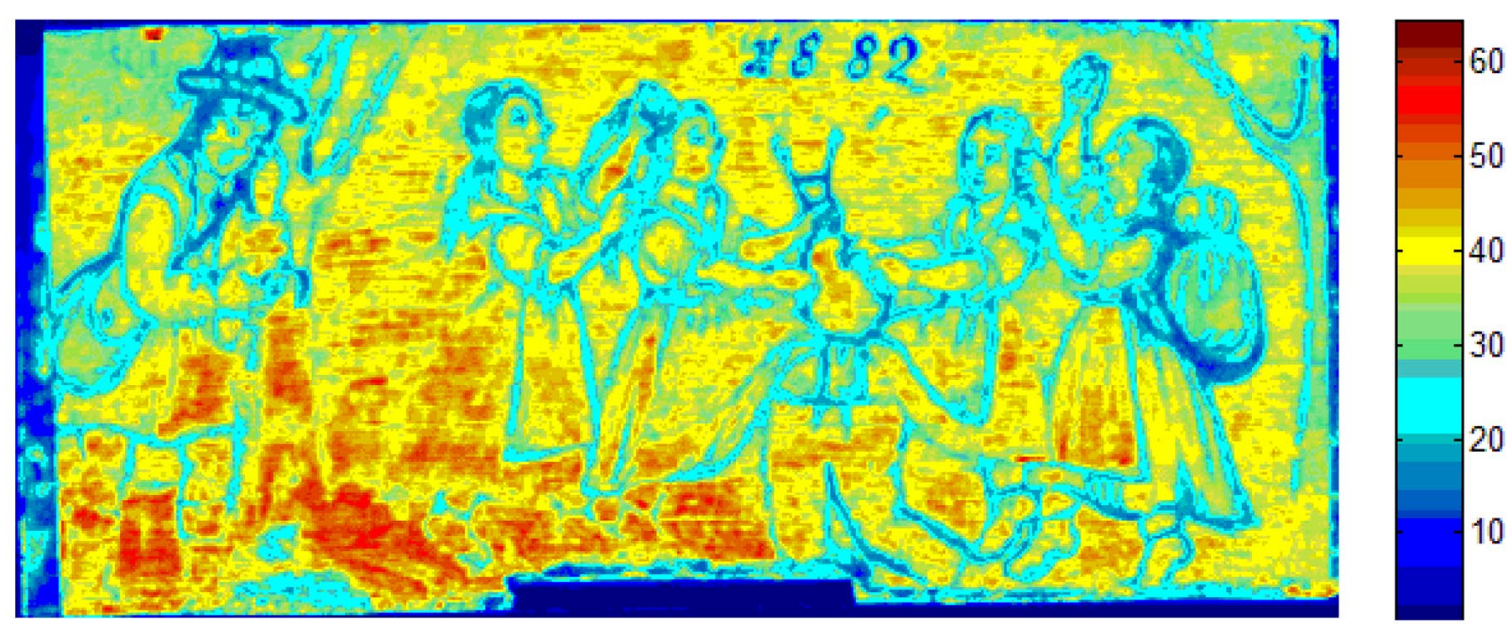

b

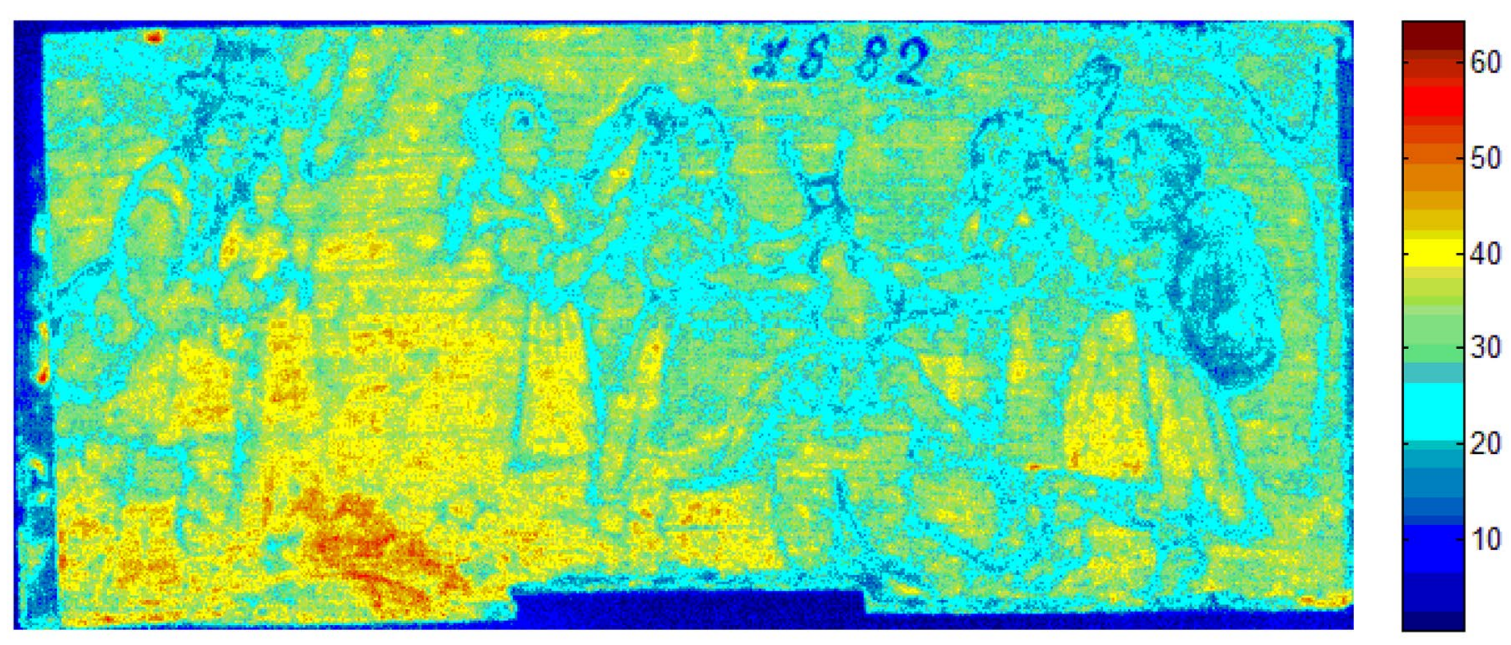

C

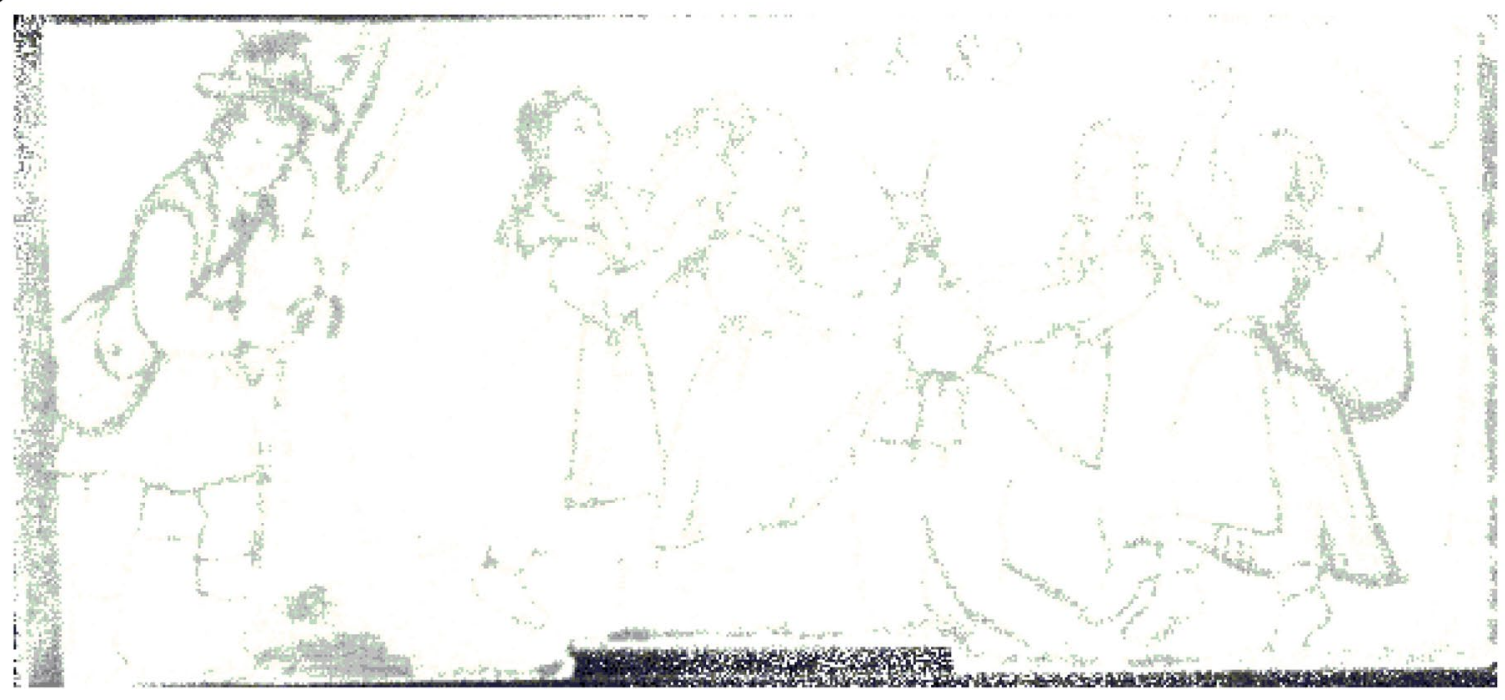


compared to the spectral features of the beeswax. This is in agreement with the item used for surface protection by the Slovene Ethnographic Museum, i.e. triterpenoid resin dammar in turpentine with addition of beeswax for matte appearance. The usual ratio of resin to wax is 10:1.

In Fig. 7c, the ratio of characteristic wavelengths for beeswax (2309 $\mathrm{nm})$ [12] and resin (1702 nm) is presented. Based on its homogeneity, it can be concluded that the mixture of resin and beeswax was applied all over the panel. This is not surprising as coatings based on a triterpenoid resin such as dammar, and likely including beeswax to decrease shine, are a commonly applied conservation treatment. The coating is also seen as a fluorescent film under UV-radiation and covers paint losses as well (Fig. 1b). The resin and the beeswax were detected in the uppermost transparent layer of the raw samples as analysed by transmission FTIR. In only one location (PK22 ), carnauba wax was detected by means of transmission FTIR, which often accompanies beeswax in wax pastes, further indicating that waxes were part of a surface layer.

The hyperspectral images showed a uniform distribution of wax on the panel surface; therefore, waxes are most likely part of the resin varnish. However, beeswax could have been secreted by bees as well, depending on how thorough conservation cleaning was. Important information could potentially be obtained from such "original" wax. Chemical characterisation of beeswax using GC-MS can enable nestmate recognition based on fatty acid composition. Beeswax plays a role in the chemical communication within a honey bee colony and provides a chemical signature so that subtle differences in its composition may be important and have never been studied historically. Isotope ratio mass spectrometry (IRMS) was found to be very useful in establishing the geographical origin of beeswax [25]. All of this indicates that much can still be learned from historical beehive panels provided that contemporary coatings have not obscured such crucial information.

Glycerolipids are the likely paint binding medium as they were detected in all non-invasive reflection FTIR measurements and in paint layers of PK2-1, PK2-2 and PK2-3 using transmission FTIR. Other organic compounds such as oxalate were also found in the reflection and transmission FTIR spectra (distinctive absorption band at $\sim 1322 \mathrm{~cm}^{-1}$ in the spectrum of PK2-1 (Figs. 4b, $5 c)$. According to the literature, metal oxalates are often found on cultural heritage objects $[26,27]$ as products of deterioration. They form during oxidative degradation of organic compounds, possibly mediated by micro-organisms and/or metal ions from the environment [28-30].

In the IR spectrum of PK2-1, metal carboxylates were also confirmed (sharp bands at 1550 and1536 cm $\mathrm{cm}^{-1}$, Fig. 5c) and these compounds were already described in the literature [31].

\section{Investigation of the support}

Optical micrograph of the cross-section of PK2-3 (Fig. 8) shows that all the paint layers were removed as the wood structure is clearly visible. This sampling location is marked with a white circle A in Fig. 9, and was used to derive reference spectral features for wood in order to perform hyperspectral analysis of distribution of exposed wood. The red areas in the false-colour image in Fig. 9 represent such features. Sampling was also undertaken in the locations $B$ and $C$, confirming the validity of this analysis of hyperspectral images. Another areas with high intensities (red) match to the most degraded surface of the object, where only wood is present.

Despite the intensive signal for wood, signals can be observed for other materials, superimposed on wood. These are in areas that are best preserved, such as contours and certain painted areas. These areas are probably less UV sensitive; typically, the areas with carbon-based black.

Correlations between resin (Fig. 7a), wax (Fig. 7b) and wood (Fig. 9) distribution can explain a more intensive deposit of the resin and wax mixture in the porous areas of exposed wood compared to areas coated with paint.

\section{Conclusions}

Relatively large collections of painted beehive panels, which are relatively uniform objects, represent an interesting source for systematic studies under various aspects. Therefore, a comprehensive material characterisation of a painted beehive panel was carried out using FTIR and Raman spectroscopy, gas chromatography coupled to mass spectrometry and hyperspectral imaging. The investigated object was degraded, likely as a consequence of outdoor weathering. As such it represented a complex analytical problem requiring complementary analytical techniques.

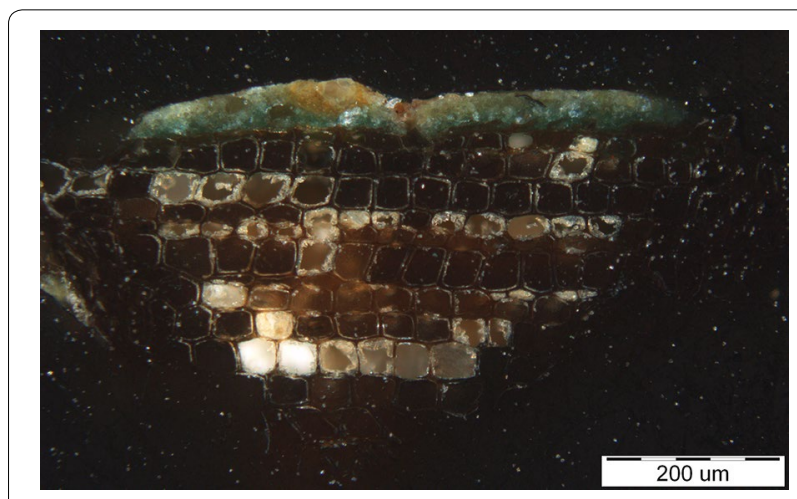

Fig. 8 Optical micrograph of the cross-section of the sample PK2-3 


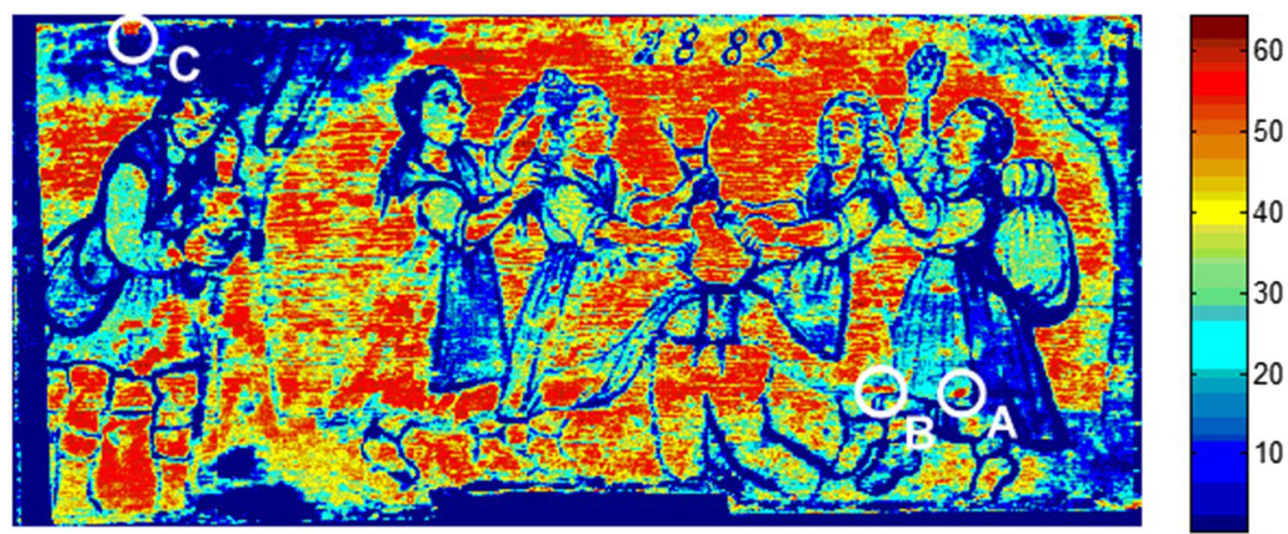

Fig. 9 False-colour image highlighting wood spectral features. Higher numbers (red colours) represent higher reflectance intensity

Many different compounds were identified using Raman and FTIR spectroscopy and GC-MS analysis representing pigments and their components (cinnabar/ vermillion, iron oxide, lead oxide, iron hydroxide, carbon-based black, Prussian blue, ultramarine, lead white, calcium carbonate, barium sulfate, anatase, chrome yellow and possibly Emerald green) as well as binders (possibly linseed oil). A surface varnish, likely applied during some past conservation treatment, was identified as a mixture of a plant terpenoid resin and beeswax, with a possible addition of carnauba wax. Compounds indicative of degradation were identified such as oxalates and carboxylates.

Hyperspectral imaging was used in this study to investigate the distribution of beeswax and plant terpenoid resin, as these materials were used for conservation. We will explore in the future whether beehive panel pigments could be mapped as well.

Prussian blue was identified in many locations using FTIR and Raman spectroscopy and the conclusion was made that it was used as a background colour.

Beeswax, however, could have two origins and some of it could have been deposited by bees themselves. Studying these depositions might allow us to understand bee activities at the entry into the beehive or their affinity for different colours. Beeswax may also hold clues as to the origin of panels, however, this may no longer be possible due to the varnish, which represents the second source of beeswax.

This study represents a comprehensive material study of a painted beehive panel and will serve as the blueprint for further analysis of objects in the extensive collections of such panels in Slovenian museums, with the aim to develop a procedure for condition evaluation. Based on this preventive conservation strategies and storage recommendations could be developed in the future.

\section{Supplementary information}

Supplementary information accompanies this paper at https://doi. org/10.1186/s40494-020-00468-y.

Additional file 1. Raman and infrared spectroscopy experimental data.

\section{Acknowledgements}

This study is part of the InnoRenew CoE project (start-up project 6.1. Advanced materials for cultural heritage storage). The authors are grateful to the Slovene Ethnographic Museum for allowing access to the painted beehive panel. Douglas Gourlay, Domen Kranjc and Ana Penko are acknowledged for their help with the analyses.

\section{Authors' contributions}

IKC and KR are developed the concept of the research and drafted the manuscript. YG and JG carried out hyperspectral imaging and data processing. $K R$, MK, LL, PR were involved in FTIR and Raman analyses. IKC carried out GC-MS analyses. All authors contributed to data interpretation and writing. All authors read and approved the final manuscript.

\section{Funding}

This research was co-funded by the EU Horizon 2020 Framework Programme (H2020 WIDESPREAD-2-Teaming: \#739574), Investment funding of Republic of Slovenia and European regional Development Fund. The work was also financially supported by the research programme P1-0153, funded by the Slovenian Research Agency.

\section{Availability of data and materials}

All data generated or analyzed during this study are included in this published article and additional material provided with the article.

\section{Competing interest}

The authors declare that they have no competing interests.

\section{Author details}

${ }^{1}$ Institute for the Protection of Cultural Heritage of Slovenia, Conservation Centre, Research Institute, Poljanska 40, 1000 Ljubljana, Slovenia. ${ }^{2}$ Faculty of Chemistry and Chemical Technology, University of Ljubljana, Večna pot 113, 1000 Ljubljana, Slovenia. ${ }^{3}$ Museum Conservation Institute, Smithsonian Institution, 4210 Silver Hill Rd., Suitland, MD 20746, USA. ${ }^{4}$ Slovene Ethnographic Museum, Metelkova ulica 2, 1000 Ljubljana, Slovenia. ${ }^{5}$ Clyde Hyperspectral Imaging \& Technology Limited, Clydebank, UK. ${ }^{6}$ UCL Institute for Sustainable Heritage, 14 Upper Woburn Place, London WC1H ONN, UK.

Received: 10 July 2020 Accepted: 13 November 2020

Published online: 26 November 2020 


\section{References}

1. Digital collection of beehive panels. https://www.etno-muzej.si/sl/panjs ke-koncnice. Accessed 8 Jun 2020.

2. Digital collection of painted beehive panels; Part 1 and Part 2. https:// mro.si/wordpress/zbirke/zbirke-in-gradivo/poslikane-panjske-koncnice1-del. https://mro.si/wordpress/zbirke/zbirke-in-gradivo/poslikane-panjs ke-koncnice-2-del. Accessed 8 Jun 2020

3. Vurnik S. Slovenske panjske končnice. Etnolog. 1929;3:157-78.

4. Bukovec A. Naše panjske končnice. Slov čebelar. 1942;45:85-90.

5. Makarovič G, Rogelj Škafar B. Poslikane panjske končnice: Zbirka Slovenskega etnografskega muzeja [Painted beehive panels: The collection of the Slovene Ethnographic Museum]; Židov N, editor. Ljubljana: Slovenski etnografski muzej: Ljubljana; 2000

6. Madariaga JM. Analytical chemistry in the field of cultural heritage. Anal Methods. 2015;7:4848-76.

7. Mazzeo R, editor. Analytical chemistry for cultural heritage. Topics in current chemistry collections. Cham: Springer; 2017.

8. Šefcu R, Pitthard V, Chlumska Š, Turkova I. A multianalytical study of oi binding media and pigments on Bohemian Panel Paintings from the first half of the 14th century. J Cult Herit. 2017;23:77-86. https://doi. org/10.1016/j.culher.2016.10.003.

9. Stanzani E, Bersani D, Paolo P, Colomban P. Analysis of artist 's palette on a 16th century wood panel painting by portable and laboratory Raman instruments. Vib Spectrosc. 2016;85:62-70. https://doi.org/10.1016/j.vibsp ec.2016.03.027.

10. Delaney JK, Thoury M, Zeibel JG, Ricciardi P, Morales KM, Dooley KA. Visible and infrared imaging spectroscopy of paintings and improved reflectography. Herit Sci. 2016. https://doi.org/10.1186/s40494-016-0075-4.

11. Dooley KA, Conover DM, Glinsman LD, Delaney JK. Complementary standoff chemical imaging to map and identify artist materials in an early Italian renaissance panel painting. Angew Chemie Int Ed. 2014;53:137759. https://doi.org/10.1002/anie.201407893.

12. Delaney JK, Dooley KA, Radpour R, Kakoulli I. Macroscale multimodal imaging reveals ancient painting production technology and the vogue in Greco-Roman Egypt. Sci Rep. 2017;7:1-12. https://doi.org/10.1038/ s41598-017-15743-5.

13. Manzano E, Rodriguez-Simón LR, Navas N, Checa-Moreno R, RomeroGámez M, Capitan-Vallvey LF. Study of the GC-MS determination of the palmitic-stearic acid ratio for the characterisation of drying oil in painting La Encarnación by Alonso Cano as a case study. Talanta. 2011:84:1148-54. https://doi.org/10.1016/j.talanta.2011.03.012.

14. Andreotti A, Bonaduce I, Colombini MP, Gautier G, Modugno F, Ribechini E. Combined GC/MS analytical procedure for the characterization of glycerolipid, waxy, resinous, and proteinaceous materials in a unique paint microsample. Anal Chem. 2006;78:4490-500. https://doi.org/10.1021/ ac0519615.

15. Bonaduce I, Carlyle L, Colombini MP, Duce C, Ferrari C, Ribechini E, Selleri P, Tiné MR. New insights into the ageing of linseed oil paint binder: a qualitative and quantitative analytical study. PLoS ONE. 2012;7:e49333. https://doi.org/10.1371/journal.pone.0049333.

16. Burgio L, Clark RJ. Library of FT-Raman spectra of pigments, minerals, pigment media and varnishes, and supplement to existing library of Raman spectra of pigments with visible excitation. Spectrochim Acta Part A Mol Biomol Spectrosc. 2001;57:1491-521. https://doi.org/10.1016/S1386 -1425(00)00495-9.

17. Bell IM, Clark RJH, Gibbs PJ. Raman spectroscopic library of natural and synthetic pigments (pre- $\approx 1850 \mathrm{AD}$ ). Spectrochim Acta Part A Mol Biomol Spectrosc. 1997;53:2159-79. https://doi.org/10.1016/S1386 $-1425(97) 00140-6$
18. Eastaugh N, Walsh V, Chaplin T, Siddall R. The pigment compendium: a dictionary of historical pigments. Abingdon: Routledge; 2008.

19. Frost RL. Raman microscopy of selected chromate minerals. J Raman Spectrosc. 2004;35:153-8. https://doi.org/10.1002/jrs.1121.

20. Monico L, Janssens K, Hendriks E, Brunetti BG, Miliani C. Raman study of different crystalline forms of $\mathrm{PbCrO} 4$ and $\mathrm{PbCr} 1-x \mathrm{SxO} 4$ solid solutions for the noninvasive identification of Chrome yellows in paintings: a focus on works by Vincent van Gogh. J Raman Spectrosc. 2014;45:1034-45. https:// doi.org/10.1002/jrs.4548.

21. Miliani C, Rosi F, Brunetti BG, Sgamellotti A. In situ noninvasive study of artworks: the MOLAB multitechnique approach. Acc Chem Res. 2010;43:728-38. https://doi.org/10.1021/ar100010t.

22. Miliani C, Rosi F, Daveri A, Brunetti BG. Reflection infrared spectroscopy for the non-invasive in situ study of artists' pigments. Appl Phys A. 2012;106:295-307. https://doi.org/10.1007/s00339-011-6708-2.

23. Brambilla L, Riedo C, Baraldi C, Nevin A, Gamberini MC, D'Andrea C, Chiantore O, Goidanich S, Toniolo L. Characterization of fresh and aged natural ingredients used in historical ointments by molecular spectroscopic techniques: IR, Raman and fluorescence. Anal Bioanal Chem. 2011:401:1827-37. https://doi.org/10.1007/s00216-011-5168-z.

24. Rosi F, Legan L, Miliani C, Ropret P. Micro transflection on a metallic stick: an innovative approach of reflection infrared spectroscopy for minimally invasive investigation of painting varnishes. Anal Bioanal Chem. 2017. https://doi.org/10.1007/s00216-017-0260-7.

25. Svečnjak L, Chesson LA, Gallina A, Maia M, Martinello M, Mutinelli F, Necati Muz M, Nunes FM, Saucy F, Tipple BJ, Wallner K, Waś E, Waters AT. Standard methods for Apis mellifera beeswax research. J Apic Res. 2019;58:1-108. https://doi.org/10.1080/00218839.2019.1571556.

26. Prieto B, Edwards HGM, Seaward MRD. A Fourier Transform-Raman Spectroscopic Study of Lichen Strategies on Granite Monuments. Geomicrobiol J. 2000;17:55-60. https://doi.org/10.1080/014904500270495.

27. Rampazzi L, Andreotti A, Bonaduce I, Colombini MP, Colombo C, Toniolo L. Analytical investigation of calcium oxalate films on marble monuments. Talanta. 2004;63:967-77. https://doi.org/10.1016/j.talan ta.2004.01.005

28. Gadd GM, Bahri-Esfahani J, Li Q, Rhee YJ, Wei Z, Fomina M, Liang X. Oxalate production by fungi: significance in geomycology, biodeterioration and bioremediation. Fungal Biol Rev. 2014;28:36-55. https://doi. org/10.1016/j.fbr.2014.05.001.

29. Cariati F, Rampazzi L, Toniolo L, Pozzi A. Calcium oxalate films on stone surfaces: experimental assessment of the chemical formation. Stud Conserv. 2020:45:180-8. https://doi.org/10.1179/sic.2000.45.3.180.

30. Salvadó N, Butí S, Nicholson J, Emerich H, Labrador A, Pradell T. Identification of reaction compounds in micrometric layers from gothic paintings using combined SR-XRD and SR-FTIR. Talanta. 2009;79:419-28. https://doi. org/10.1016/j.talanta.2009.04.005.

31. Otero V, Sanches D, Montagner C, Vilarigues M, Carlyle L, Lopes JA, Melo MJ. Characterisation of metal carboxylates by Raman and infrared spectroscopy in works of art. J Raman Spectrosc. 2014;45:1197-206. https:// doi.org/10.1002/jrs.4520.

\section{Publisher's Note}

Springer Nature remains neutral with regard to jurisdictional claims in published maps and institutional affiliations. 